\title{
Tissue-Specific Ageing of Rat Tendon-Derived Progenitor Cells
}

\section{Nanette Scutt ${ }^{1}$, Adiv A. Johnson ${ }^{2}$, Andrew Scutt ${ }^{1,5}$ and Alexandra Stolzing ${ }^{3,4 *}$}

${ }^{1}$ Department of Engineering Materials, Kroto Research Institute, University of Sheffield, Sheffield, UK

${ }^{2}$ Department of Ophthalmology, Mayo Clinic, Rochester, Minnesota, USA

3IZBI, University of Leipzig, Germany

${ }^{4}$ Centre for Biological Engineering, Wolfson School, Loughborough University, Loughborough, UK

${ }^{5}$ College of Medicine, Swansea University, Wales, UK

\begin{abstract}
Although ageing predisposes tendons for various pathologies, the effect of ageing on tendon stem/progenitor cells has received little attention. In this study, we compared tendon progenitor cells from patellar, Achilles and tail tendons derived from young (8-12 weeks old) and mature ( 52 weeks old) rats. The mean number of progenitor cells/ $\mathrm{mg}$ was reduced with age in all three tendons and this reduction reached statistical significance in both Achilles and tail tendons. As determined by colony-forming-unit-fibroblasts assays, mean colony number and size were both statistically unchanged with age in patellar and Achilles tendons. In contrast, both colony number and size were significantly reduced in cultures derived from mature tail tendons relative to those derived from young tail tendons. While colonies per mg tissue were reduced with age in all three tendons, this reduction was only statistically significant for tail tendon. Lipofuscin and ROS content in cell progenitors were unchanged with age in all 3 tendons. Conversely, carbonyl content was significantly increased and telomerase activity significantly decreased in mature tail tendon cells relative to young tendon cells. These data suggest that, in the first year of life, rat Achilles and patellar tendons suffer relatively little oxidative damage. In contrast, tail tendons experience an increase protein oxidation, a decrease in telomerase activity and a substantial reduction in progenitor cell numbers. That the source and age of tendon progenitors used influences the quality and density of the progenitor cells isolated from it has important implications for clinical strategies aimed at tendon repair.
\end{abstract}

Keywords: Tendon; Aging; Progenitors; Stem cells; CFU-f

\section{Introduction}

The normal ageing process gives rise to a series of degenerative changes in connective and musculoskeletal tissues. These changes lead to increased frailty, a decline in functional competence and a reduction in the ability to cope with bodily stresses $[1,2]$. Tendons are no exception and ageing has long been known to predispose tendons for numerous pathologies $[1,3]$. The incidence of quadriceps, patellar and Achilles tendon rupture increases progressively with age [4]. Likely due in part to the ever-growing aging population, injuries in the elderly due to falls, slips and trips have increased over $100 \%$ in the past $30-40$ years and, in those aged over 65 , sports-related soft tissue injuries have increased over 50\% [5-7]. Exercise, which attenuates the major hallmarks of aging [8], significantly increases the thickness of patellar tendons in the elderly [9]. Tendon healing can take up to a year to complete and often leads to the development of an inferior matrix with poorer mechanical properties. As connective tissue healing generally becomes impaired with age $[10,11]$, it is likely that poor tendon healing is exacerbated in the elderly. This has been shown to be the case in a rat model of rotator cuff repair, where aging diminished tendon-to-bone healing [12].

Although it is known that tendon ageing affects biomechanical properties and extracellular matrix metabolism [13], there is little known about cellular ageing in tendons. It has, however, been previously reported that tendon cell density is reduced with age. For example, in equine digital tendons, there is a progressive loss in tenocyte density (expressed as cells $/ \mathrm{mm}^{2}$ ) as horses age from foal (1-6 months) to young adult (2-7 years) to mature (18-33 years) [14]. It was similarly found that fibroblast number is reduced with age in rabbit Achilles tendons [15]. Tendon cellularity was also shown to significantly decline with age in the patellar tendons of both Fisher 344 and Fisher-Brown-Norway rats [16]. As tenocytes are largely non-proliferative in vivo, it has been assumed that the reduction in cell density is due to increased tendon size with age. Nevertheless, age related changes in proliferative capacity have been noted. A trend towards a lower proliferative response to platelet-derived growth factor was previously reported in old versus young rats [16]. A slight age-related decline in growth characteristics was also found in fibroblasts extracted from human biceps tendons with an age range of 11-83 years [17]. Furthermore, cells from aged mouse Achilles tendons displayed lower proliferation in culture than those obtained from young mice [3].

Other age-related effects in tendons have been observed, particularly with respect to cell morphology. With age, rabbit tenoblasts become longer and more slender [18]. Rabbit ageing has also been reported to decrease the number of tendon cells per unit of tissue surface by increasing extracellular matrix volume [18]. Fibroblasts from various murine tendons analogously exhibit dysfunction and abnormal morphology $[3,19]$. In mice, tendon stress fibres were found to be highly organized in younger cells whilst those from the older animals were more disorganised. Key focal adhesion proteins were differentially localized in young and old tendon fibroblasts and aged tenocytes displayed reduced cell motility [3]. The expression of connexin 43 and 32 proteins per equine tenocyte was much higher in foetal tendon samples than in tendon samples from foals, young adults, or old horses [14]. In addition, tendon stem/progenitor cells from aged/degenerated human Achilles tendon biopsies were shown to exhibit delayed wound closure, decelerated motion and notable transcriptomal shifts [20].

*Corresponding author: Alexandra Stolzing, IZBI, University of Leipzig, Germany, Tel: +44 1509227577; E-mail: A.Stolzing@lboro.ac.uk

Received August 05, 2015; Accepted October 15, 2015; Published October 17 2015

Citation: Scutt N, Johnson AA, Scutt A, Stolzing A (2015) Tissue-Specific Ageing of Rat Tendon-Derived Progenitor Cells. J Stem Cell Res Ther 5: 309. doi:10.4172/2157-7633.1000309

Copyright: (c) 2015 Scutt N, et al. This is an open-access article distributed under the terms of the Creative Commons Attribution License, which permits unrestricted use, distribution, and reproduction in any medium, provided the original author and source are credited. 
With increasing age, oxidative damage induced by reactive oxygen species (ROS) builds up in cells, leading to the accumulation of damaged lipids, proteins and DNA. If severe enough, cells become damaged and dysfunctional [21]. To counteract this oxidative damage, cells produce a variety of antioxidant enzymes to neutralise the harmful effects of ROS, including superoxide dismutase (SOD) and catalase [21]. The importance of antioxidant enzymes in tendons is exemplified by the finding that mice lacking SOD-1 show impaired elasticity in the supraspinatus tendon enthesis [22]. Although many tissues exhibit a progressive reduction in antioxidant defences and an accumulation in oxidative damage with age, rat Achilles tendons were previously reported not to display this age-related decrease in oxidative defences [23]. However, an age-related increase in protein oxidation was reported [23].

In this study, we sought to further elucidate the effects of ageing on tendons by investigating how age impacts various parameters in tendon progenitor cells derived from rat Achilles, patellar and tail tendons. We identify novel aspects of tendon aging that have important implications for clinical strategies aimed at tendon repair.

\section{Materials and Methods}

\section{Reagents and consumables}

Unless stated otherwise, all chemicals were purchased from SigmaAldrich (Poole, Dorset, UK) and used as instructed. Tissue culture media was procured from Lonza (Wokingham, UK) and plasticware was acquired from Scientific Laboratory Supplies (Nottingham, UK).

\section{Tissue samples and preparation}

For all experiments a group of six young (8-12 weeks old) and five adult ( 52 weeks old) female Wistar rats were used. The isolated progenitor cells were not pooled and analysed independently. After the rats were sacrificed by a schedule 1 method, the patellar tendon from each knee was dissected from the surrounding tissues with sharp scissors. Both tendons were then combined for digestion. The Achilles tendons were excised at the calcaneus and the adjoining muscles with scissors and also combined for digestion. The tails were removed and a sample of the tendon fascicles was dissected from the surrounding tissues. The combined tissues were weighed prior to digestion.

Tissue samples were rinsed in tissue culture medium under sterile conditions, diced into small pieces and then digested for $18 \mathrm{hrs}$ in sterile crude collagenase solution (collagenase from Clostridium histolyticum, $1 \mathrm{mg} / \mathrm{ml}$ ) at $37^{\circ} \mathrm{C}$ on a rotary blood mixer, thereby digesting the majority of the collagen in the sample and freeing the progenitor cells into the medium. Following digestion, the sample was filtered through a 70 micron cell sieve and washed. The cell number was evaluated by flow cytometry using a Guava personal flow cytometry system (EMD Millipore, Billerica, Massachusetts, USA) and Guava ViaCount (EMD Millipore).

\section{Immunophenotyping}

We performed immunophenotyping in a similar manner to our recently published work [24]. Progenitor cells up to passage 3 were harvested by trypsinization and stained with antibodies against CD44 (1:100) and CD90 (1:100). Progenitor cells were incubated at $4^{\circ} \mathrm{C}$ for $30 \mathrm{~min}$ and subsequently stained with $\mathrm{PE}$ conjugated anti-mouse $\operatorname{IgG}\left(1: 100 ; 30 \mathrm{~min} ; 4^{\circ} \mathrm{C}\right)$. All antibodies were obtained from Serotec (Oxford, UK). The progenitor cells were analysed using a Guava personal flow cytometry system (EMD Millipore).

\section{Growth Curve}

To assess the growth kinetics of progenitor cells derived from young and mature tendons, a standard growth curve experiment was performed on 3 sets of young and 3 sets of mature tail and Achilles tendon progenitor cells. The progenitor cells were plated into T25 flasks at a concentration of $5 \times 10^{3}$ cells $/ \mathrm{cm}^{2}$ in DMEM containing $10 \%$ FCS and grown until $90 \%$ confluent. They were then serially sub-cultured until the progenitor cells stopped dividing. The number of population doublings (PD) was calculated using the following formula, where $\mathrm{N}$ is the number of cells at the end of the growth period and $\mathrm{N}_{0}$ is the number of cells plated in the flask: $P D=\log _{10}\left(N / N_{0}\right) \times 3.33$

\section{Fibroblastic-Colony-Forming-Unit Cultures}

Fibroblastic-colony-forming-unit culture (CFU-f) assays were performed in triplicates using a method originally established for the analysis of CFU-f in bone marrow but adapted for use with tendon progenitor cells [25-27]. Briefly, $1 \times 10^{3}$ primary progenitor cells generated from tendon digests were plated out in $55 \mathrm{~cm}^{2}$ petri dishes in Dulbecco's modified Eagle's medium containing $10 \%$ foetal calf serum, penicillin/streptomycin and ultra-glutamine. After 5 days the medium was replaced and thereafter twice weekly. The cultures were maintained for 11 days, after which time the progenitor cells were washed with phosphate-buffered saline and subsequently fixed by the addition of cold ethanol. After fixation, the cultures were stained for total colonies with $0.1 \%$ methylene blue in $10 \mathrm{mM}$ borate buffer ( $\mathrm{pH}$ 8.8) for $30 \mathrm{~min}$. Excess stain was then removed by washing under running tap water. The cultures were dried, photographed and analysed using Gene Tools (Syngene, Cambridge, UK) or Intelligent Quantifier (Bio Image Systems, Jackson, USA) image analysis software to calculate the number and size of colonies.

\section{Reactive oxygen species measurements}

ROS were determined by the uptake and oxidation of Dichlorofluorescin diacetate (DCF-DA). Cell suspensions (approximately $1 \times 10^{5}$ ) were washed, resuspended in freshly diluted DCF-DA solution at a concentration of $10 \mu \mathrm{M}$ and then incubated at $37^{\circ} \mathrm{C}$ for $30 \mathrm{~min}$. Samples were washed twice before measuring the fluorescence intensity in the Guava personal cell analysis system using the Protein Express Software package. Progenitor cells at passages 1-3 were used.

\section{Autofluorescence and lipofuscin measurements}

Measurements of autofluorescence and lipofuscin were done according to a previously described protocol by Sheehy [28]. Unstained cell suspensions were washed in media and then assayed in the Guava personal cell analysis system to look for any autofluorescence using the Protein Express software package. Progenitor cells at passages 1-3 were used.

\section{Cell number}

Cell number was assessed by the method of Currie [29]. After fixation, the progenitor cells (passages 1-3) were washed with borate buffer $(10 \mathrm{mM}$, $\mathrm{pH} 8.8$ ), stained with $1 \%$ methylene blue in borate buffer for $30 \mathrm{~min}$ and then rewashed three times with borate buffer. Bound methylene blue was eluted with $1 \% \mathrm{HCl}$ in ethanol and the absorbance measured at $650 \mathrm{~nm}$. All animals were analysed independently using technical triplicates.

\section{Determination of antioxidant capacity}

Progenitor cells (passages 1-3) were pelleted and SOD activity, catalase activity and total antioxidant capacity measured using commercial kits according to the manufacturer's instructions (Cayman Chemicals, Ann Arbor, Michigan, USA). Progenitor cells were sonicated 
and centrifuged for $10 \mathrm{~min}$ at $1500 \mathrm{~g}$. The supernatant was added to a 96 well plate and the samples, enzymes and buffer were then added. The absorbance was measured at $440 \mathrm{~nm}, 540 \mathrm{~nm}$ or $750 \mathrm{~nm}$ for SOD, catalase and total antioxidant capacity, respectively. Absorbances were measured together with SOD, catalase or total antioxidant standards included with the used commercial kits.

\section{Telomere length}

Quantification of the relative telomere length was done according to a modified version of a previously published protocol [30]. Real-time, quantitative PCRs were performed to evaluate the ratio of telomeric repeats (T) and single copy gene (S) 36B4 in separate 96-well plates. Genomic DNA from HeLa cells was used as standard. Genomic DNA of cells was isolated, blended with TE buffer (containing $1 \mathrm{M}$ Tris- $\mathrm{HCl}$, $0.25 \mathrm{M}$ EDTA; $\mathrm{pH} 7.5$ ), heated at $95^{\circ} \mathrm{C}$ for $5 \mathrm{~min}$ and chilled immediately in ice water for $5 \mathrm{~min}$. The primers used were $\left(5^{\prime} \rightarrow 3^{\prime}\right)$ : telo 1 , CGG TTT [GTT TGG] ${ }_{5}$ GTT; telo 2, GGC TTG [CCT TAC] ${ }_{5}$ CCT; 36B4d, CCC ATT CTA TCA TCA ACG GGT ACA A; 36B4u, CAG CAA GTG GGA AGG TGT AAT CC.

\section{Telomerase activity}

A modified protocol based on Wege et al. [31] and Herbert et al. [32] was utilized to measure telomerase activity by a real-time telomerase SYBR green TRAP assay. Cell pellets were resuspended in ice cold TRAP buffer containing Diethylpyrocarbonate- $\mathrm{H}_{2} \mathrm{O}, 1 \mathrm{M}$ Tris- $\mathrm{HCl}$ (pH 8.0), $1 \mathrm{M} \mathrm{MgCl}, 250 \mathrm{mM}$ EDTA, NP-40, $20 \mathrm{mM} \mathrm{Na}-$ Deoxycholate, Glycerol, $3 \mathrm{M} \mathrm{NaCl}$ and $3 \mathrm{M} \beta$-Mercaptoethanol blended with 4-(2-Amino-ethyl-)benzensulfonylfluorid (EMD Millipore), followed by incubation on ice for $30 \mathrm{~min}$. Cells were then centrifuged at $16,000 \mathrm{~g}$ for $20 \mathrm{~min}$ at $4^{\circ} \mathrm{C}$. The supernatant was collected and its protein concentration was determined with the Qubit ${ }^{\circ}$ protein assay kit (Life Technologies, Carlsbad, California, USA). We used the telomerase primers $\left(5^{\prime} \rightarrow 3^{\prime}\right)$ TS, AAT CCG TCG AGC AGA GTT AG [GGT TAG] ${ }_{4-}$ ${ }_{7}$ and ACX, GCG CGG [CTT ACC] ${ }_{3}$ CTA ACC. PCR was performed using the LightCycler ${ }^{\circledast} 480$ (Roche Diagnostics, Basel, Switzerland).

\section{Statistics}

Statistical analyses were conducted using SigmaPlot 10.0 software (Systat Software Inc., San Jose, California, USA) and by performing One way Analysis of Variance (ANOVA) followed by Holm-Sidak-testing. $\mathrm{P}$-values $<0.05$ were considered statistically significant and marked by a single asterisk. P-values $<0.001$ were marked by triple asterisks.

\section{Results}

To investigate the effects of in vivo ageing on tendon progenitor cells, progenitor cells were obtained from a group of six 8-12 week old female Wistar rats and a group of five 52 week old ex-breeder Wistar rats. For comparison of tissues, progenitor cells from Achilles, patellar and tail tendons were used in this study. Tissues were excised and weighed, progenitor cells extracted by collagenase digestion, cell number determined and the number of progenitor cells per mg tissue calculated for each tendon group (Table 1). The mean wet-weights of the pairs of patellar and Achilles tendons were increased in the mature group by approximately $150 \%$ relative to the young group. Total cell numbers in these tendons did not decrease with age. Rather, cell numbers were increased by approximately $30 \%$ in both the patellar and Achilles tendons in the older animals. Total cell progenitor numbers could not be adequately compared for the tail tendons as only a sample of tissue was evaluated. It was found that, in both young and mature rats, cell progenitor densities were highest in the Achilles tendons followed by the patellar and tail tendons (Table 1). Despite the increase in total cell progenitor numbers and due to a proportionally larger increase in tissue wet weight, there were fewer progenitor cells per mg tissue in the mature tendons as compared to young and this difference achieved significance in the Achilles and tail tendons (Table 1). This is in agreement with findings from other groups showing that ageing reduces stem/progenitor cell numbers $[33,34]$. All isolated progenitor cells were positive for CD44 and CD90, as reported before by our group [27].

Numbers of putative stem/progenitor cells in the tendons were determined using an adapted fibroblastic-colony forming unit (CFU-f) assay. The formation of a colony in this assay was taken to be indicative of cell progenitors with appreciable proliferative capacity, although the exact nature of these cells (stem, progenitor or partially differentiated) was unknown. It seems reasonable, however, to assume that a larger colony would indicate cell progenitors with a higher proliferative capacity and at an earlier stage of differentiation. The highest number of colonies per 1000 progenitor cells seeded was found in the young tail tendon progenitor cells followed by the patellar and Achilles progenitor cells (Figure 1a). No significant difference was found between the overall number of colonies from young and mature Achilles and patellar tendons. Conversely, the mean colony number was significantly reduced in cell populations from mature tail tendons compared to cell populations from young tail tendons (Figure 1a). While mean colony size (Figure $1 \mathrm{~b}$ ) and colonies per mg of tissue (Figure 1c) were comparable in young and mature patellar and Achilles tendons, both of these parameters were significantly reduced in mature tail tendons. The number of colonies per mg of tissue was notably reduced by a factor of 10 in the tail tendons from mature rats (Figure 1c). Mean colony size, a measure of the rate of proliferation, was greatest in the patellar tendon progenitor cells followed by the Achilles tendon progenitor cells. Although mean colony number was greatest in the young tail tendon progenitor cells (Figure 1a), the colony size was smaller in cell populations from tail tendons than those from Achilles or patellar tendons (Figure 1b). Representative images showing the discernible decrease in colony size and colony number in mature tail tendons are shown in Figure 2. This was also reflected in an analysis of the colony size distribution for cell progenitor populations from Achilles (Figure $3 a)$, patellar (Figure $3 b$ ), and tail tendons (Figure 3c). The median colony size was largest in the Patellar cultures followed by the Achilles and then the tail tendons (Figure 3). The size distribution curves of the mature and young progenitor cells were similar for the Achilles and Patellar tendons, whereas the curve was skewed towards the smaller end of the scale for cell populations from tail tendons (Figure 3).

\begin{tabular}{|c|c|c|c|c|c|c|}
\hline Tissue & \multicolumn{3}{|c|}{ Young } & \multicolumn{2}{c|}{ Old } \\
\hline & Wt $(\mathrm{mg})$ & Total Cell No. $\left(\times 10^{3}\right)$ & Cells $/ \mathrm{mg}$ & Wt $(\mathrm{mg})$ & Total Cell No. $\left(\times 10^{3}\right)$ & Cells/mg \\
\hline Patellar & $20.7 \pm 3.9$ & $115 \pm 78$ & $5268 \pm 2912$ & $50.5 \pm 9.7$ & $160 \pm 73$ & $3180 \pm 1339$ \\
\hline Achilles & $46.6 \pm 8.4$ & $470 \pm 201$ & $10014 \pm 3669$ & $118.0 \pm 45.7$ & $612 \pm 73$ & $5677 \pm 1711^{*}$ \\
\hline Tail & n/a & $1446 \pm 187$ & $3984 \pm 419$ & n/a & $514 \pm 338$ & $972 \pm 607^{*}$ \\
\hline
\end{tabular}

Table 1: Mean weights and cell density of patellar, Achilles and tail tendons from young and old rats. Data are presented as mean \pm standard deviation. ${ }^{*}$ Indicates a significant difference $(p<0.05)$ compared to corresponding young tendon cells. 

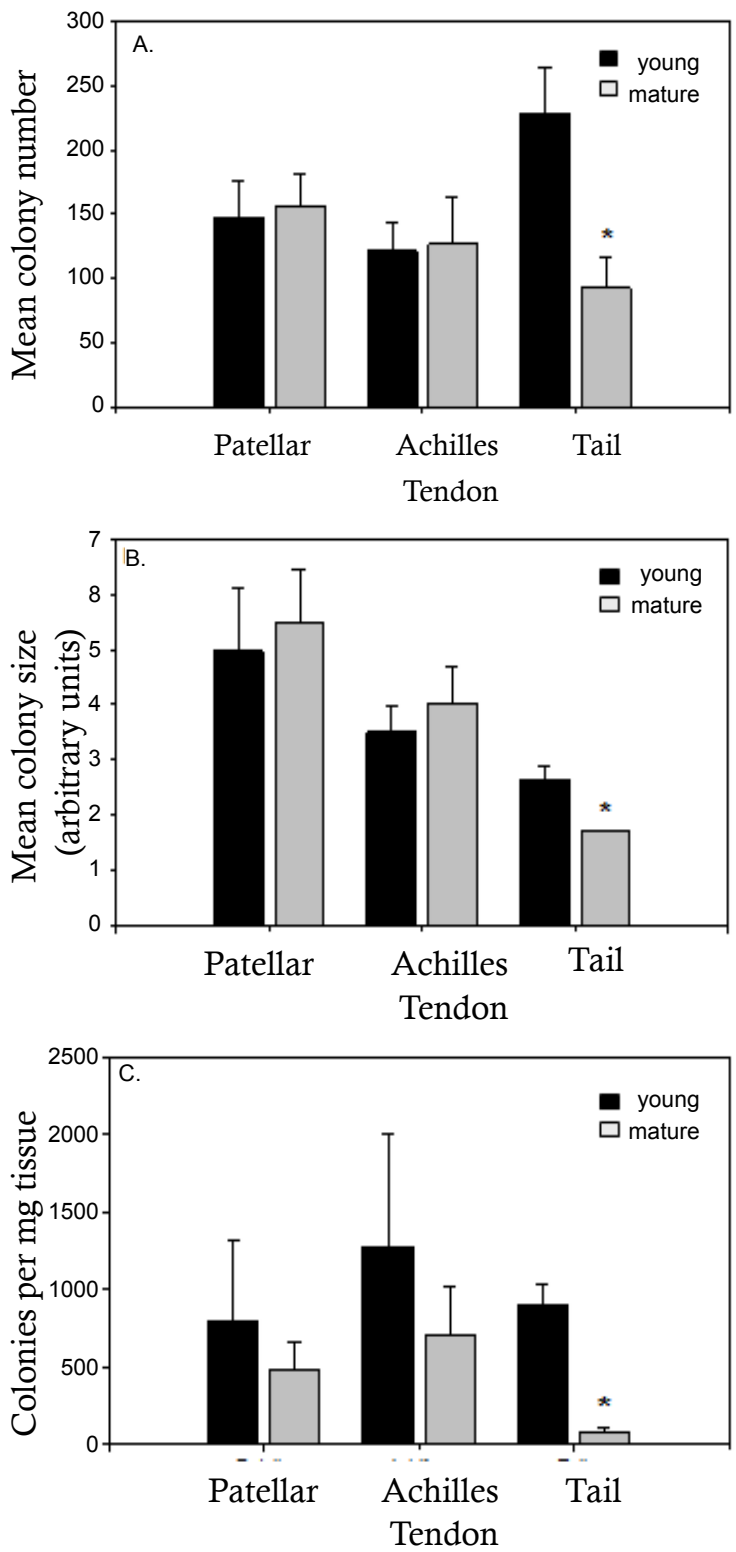

Figure 1: Effect of age on stem/progenitor cell numbers in rat Achilles, patellar and tail tendons. Primary tendon derived cells from 3 and 12 month old rats were obtained by collagenase digestion and cultured in the CFU-f assay. Mean colony number $(A)$, mean colony size $(B)$ and colonies/mg tissue (C) were determined. * indicates a significant difference $(p<0.05)$ compared to the corresponding tendons from younger animals. Data are presented as mean \pm SEM

Despite showing significant differences in colony number, size and density between mature and young tendons and different types of tendons (Figures 1-3), much less variation was seen between standard monolayer cultures. When ex vivo growth was measured in high density cultures over 4 days using methylene blue staining, there was no significant difference between mature and young Achilles, patellar or tail tendons (Figure 4a). Only the tail tendon progenitor cells showed a slight trend towards a reduced growth rate with age, although this did not achieve statistical significance (Figure 4a). Growth curves were performed on young and mature progenitor cells from Achilles and tail rat tendons to determine the effects of age on the number of population doublings (PDs) that these progenitor cells could undergo (Figure 4b).

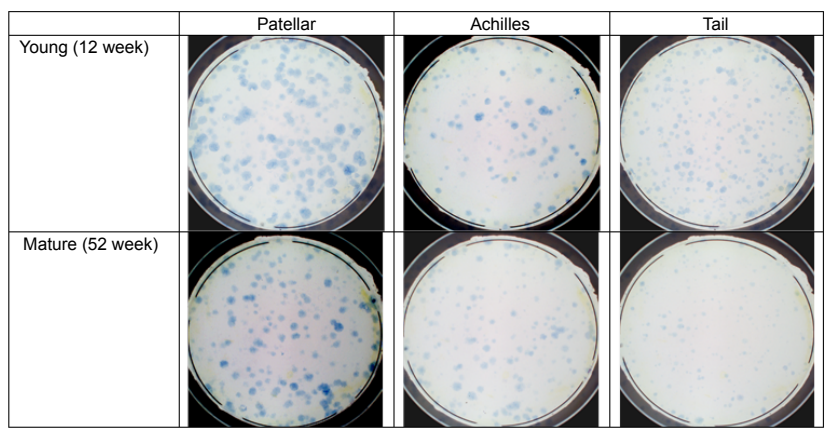

Figure 2: Representative images are shown for stem/progenitor cell cultures derived from young and mature patellar, Achilles and tail tendons. These images correspond to the cultures described in Figure 1.
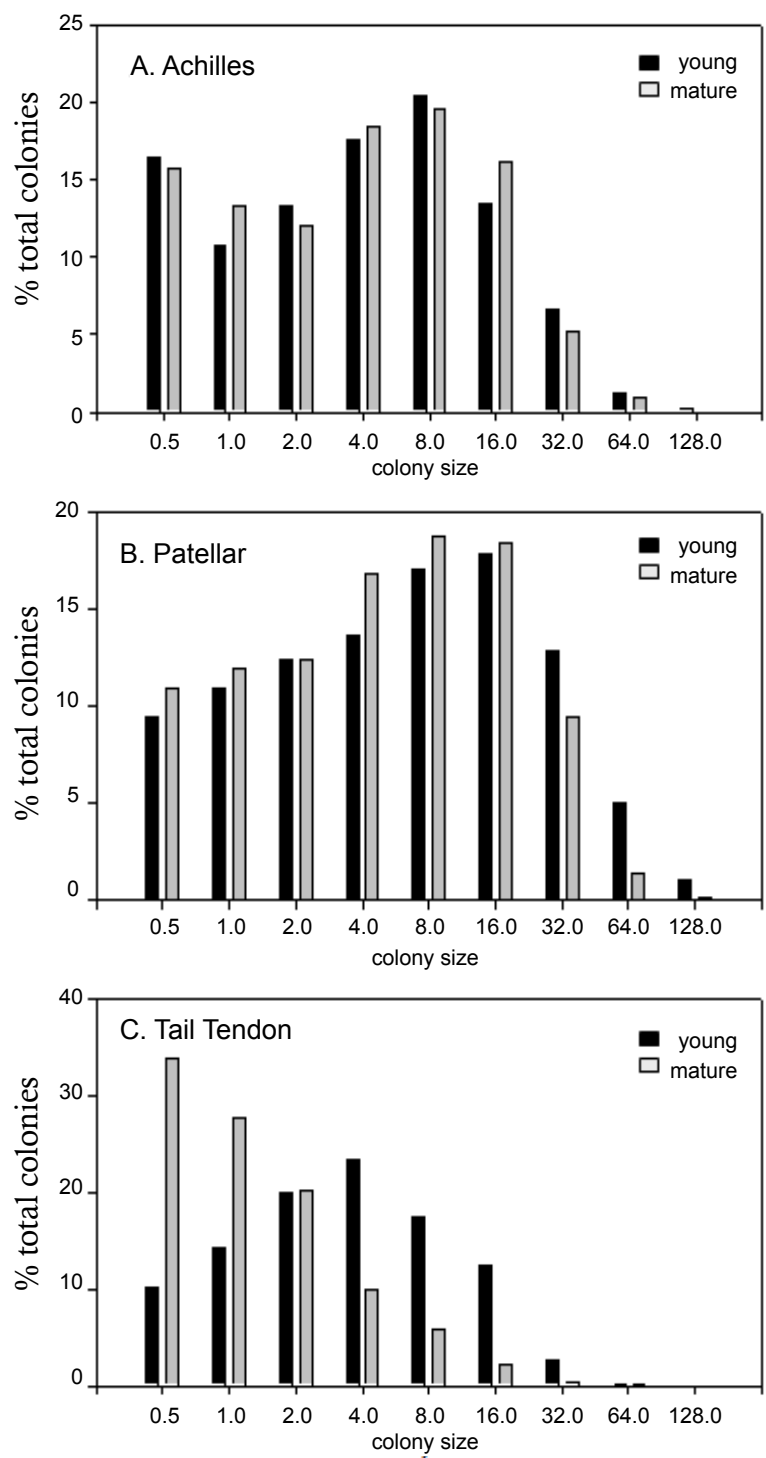

Figure 3: Effect of age on CFU-f size distribution in rat Achilles, patellar and tail tendons. Colony size distribution was calculated for stem/progenitor cells derived from young and mature Achilles (A), patellar (B) and tail (C) tendons. Data are presented as mean \pm SEM. 

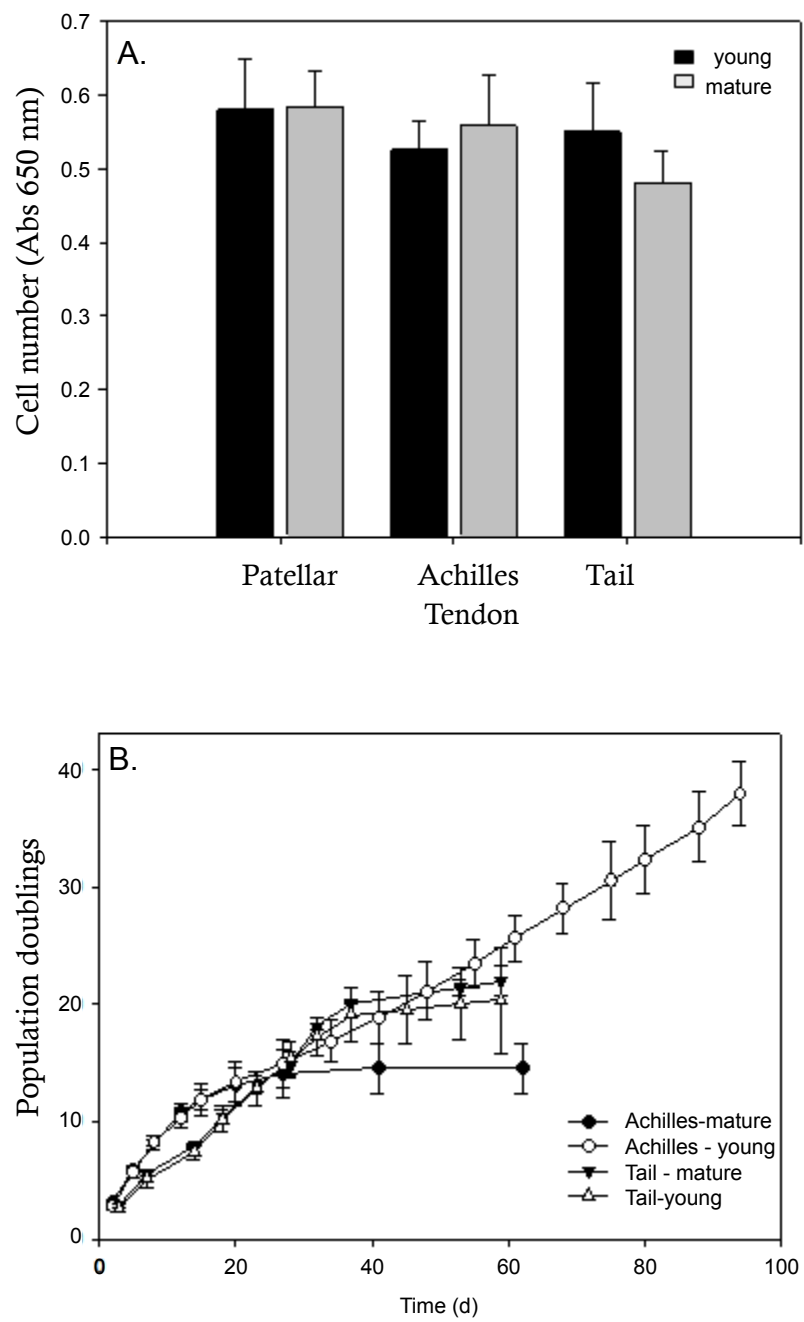

Figure 4: Effect of age on tendon stem/progenitor cell proliferation. (A) Tendon derived cells were plated out at $1 \times 10^{4}$ cells $/ \mathrm{cm}^{2}$ and allowed to grow for 4 days, after which the cells were stopped and cell number determined by methylene blue staining. (B) Growth curves were constructed by plating tendon derived cells into T25 flasks at a concentration of $5 \times 10^{3} \mathrm{cells} / \mathrm{cm}^{2}$ and allowing them to grow until they were $90 \%$ confluent. They were then serially sub-cultured until the cells ceased to divide. Data are presented as mean \pm SEM.

We find that, initially, all of the measured cell types grew at a very similar rate. After about $10 \mathrm{PDs}$, the growth rate slowed for the mature Achilles progenitor cells, reaching a plateau at about 15 PDs. The young Achilles progenitor cells continued to grow until 38 PDs for the entirety of the experiment (Figure $4 \mathrm{~b}$ ). The young and mature tail tendon progenitor cells produced essentially identical growth curves over the time course tested. They continued to proliferate up until 20-22 PDs, at which point they reached a plateau (Figure $4 b$ ).

Our previous work has implicated oxidative damage in the ageing of mesenchymal stem cells (MSCs) in rats and humans [35-37]. To further assess the effects of ageing on tendons, we next assessed markers of oxidative damage in tendons from young and old rats. Samples of ex vivo progenitor cells were assayed for the presence of lipofuscin, a marker of senescence which accumulates with age [38]. By measuring autofluorescence via flow cytometry, we found that there was very little autofluorescence in any of the samples tested (Figure 5a). The autofluorescence levels were comparable between samples, suggesting that lipofuscin does not significantly accumulate with age in tendon progenitor cells (Figure 5a). We next used flow cytometry to measure the uptake of DCF and therefore assess intracellular ROS levels. Like we found with autofluorescence, there was no significant difference between mature and young progenitor cells derived from patellar, Achilles and tail tendons (Figure $5 b$ ). We then analysed total carbonyl content, a measure of protein oxidation that increases with age in many tissues and cell types [39]. Unlike the lipofuscin and ROS data, we observed a significant increase in carbonyls in mature tail tendon progenitor cells compared to young tail tendon progenitor cells (Figure 5c). Carbonyl levels were
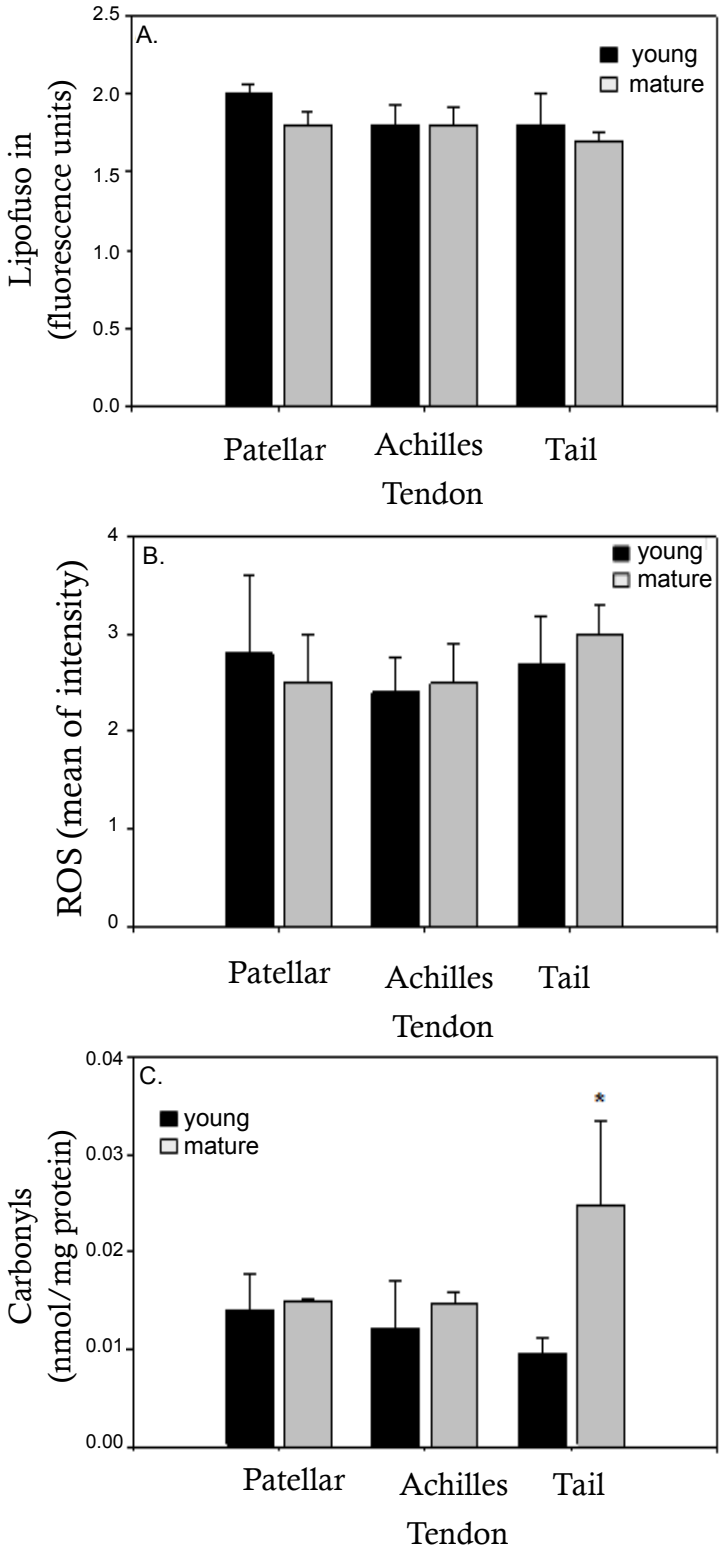

Figure 5: Effect of age on oxidative damage levels in tendon stem/progenitor cells. Primary tendon derived cells were harvested from young or old rats and lipofuscin (A), ROS (B) and carbonyl (C) levels measured. * indicates a significant difference $(p<0.05)$ compared to the corresponding tendons from younger animals. Data are presented as mean \pm SEM. 
comparable in both young and mature cells derived from either patellar or Achilles tendons (Figure 5c).

We proceeded to look at the effect of ageing on oxidative defences in tendon-derived progenitor cells. Overall antioxidant levels were found to be increased in the mature tail tendon progenitor cells but unchanged in the Achilles or patellar tendon progenitor cells (Figure 6a). SOD levels were raised with age in the Achilles tendon progenitor cells but remained unchanged in the patellar and tail tendon progenitor cells (Figure 6b). Compared to young cells from the same tendon, catalase levels were increased in mature patellar tendon progenitor cells and in mature Achilles tendon progenitor cells, though this increase was only statistically significant for patellar tendon cells (Figure 6c).
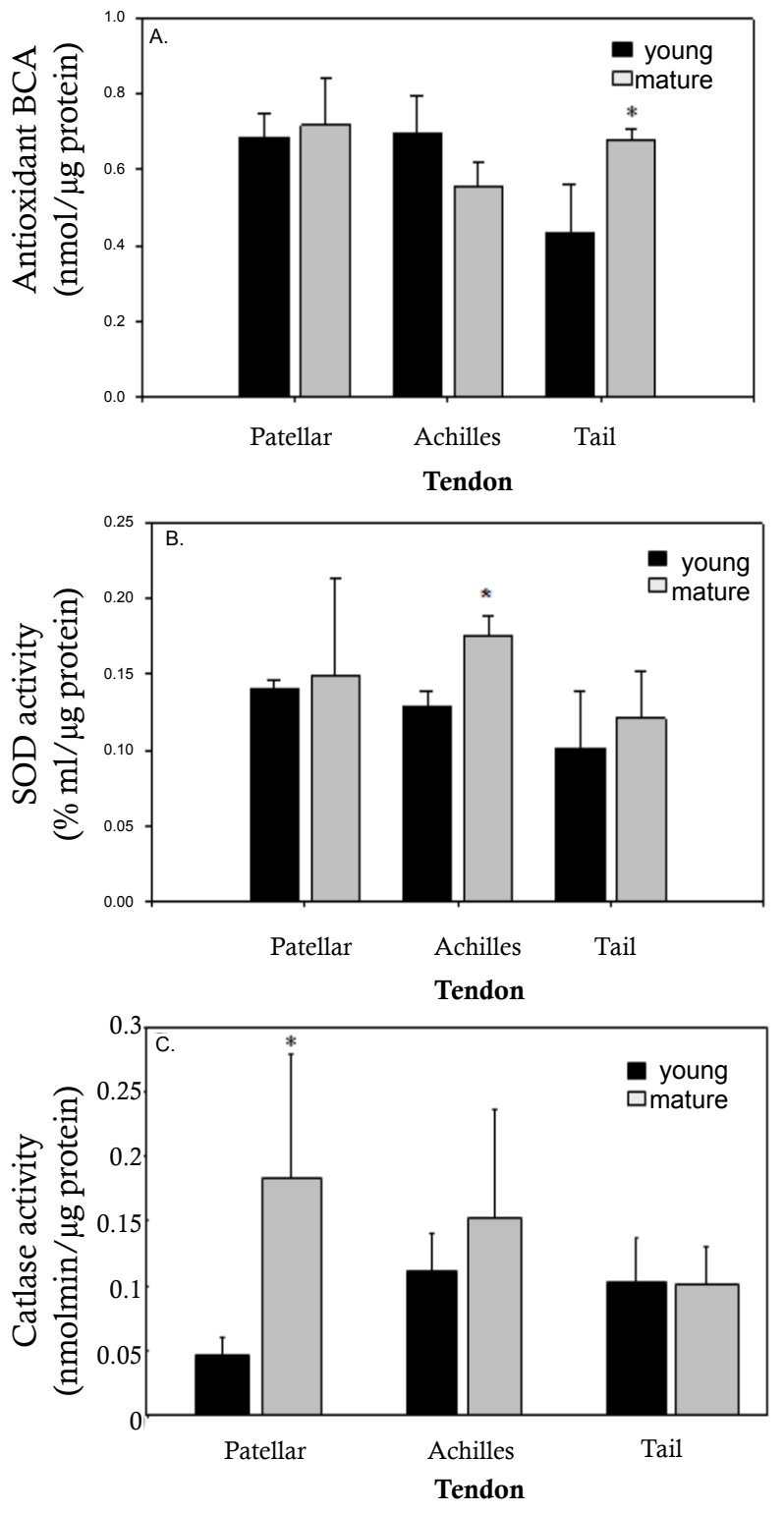

Figure 6: Effect of age on oxidative defences in tendon stem/progenitor cells. Primary tendon derived cells were harvested from young or old rats and total antioxidant levels $(A)$, SOD activity $(B)$ and catalase activity $(C)$ determined. *indicates a significant difference $(p<0.05)$ compared to the corresponding tendons from younger animals. Data are presented as mean \pm SEM.
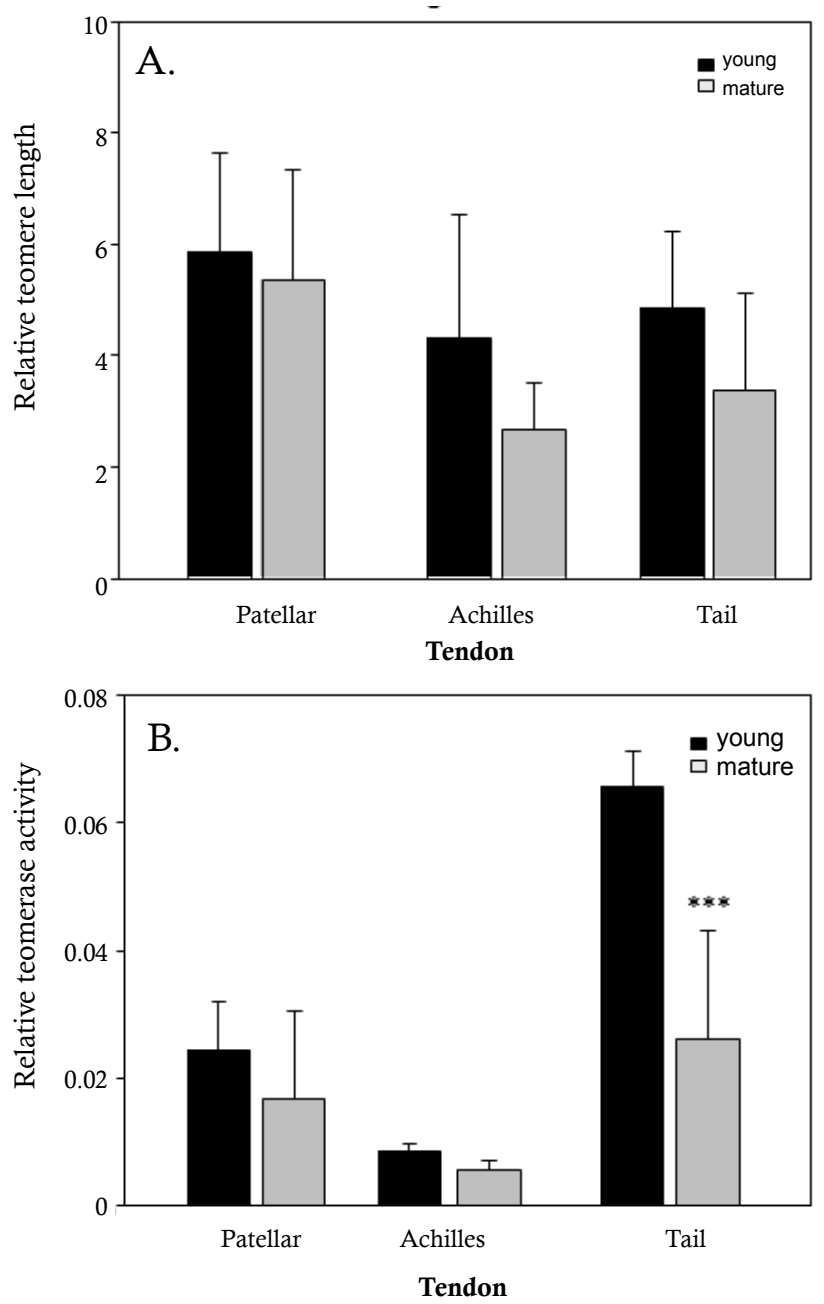

Figure 7: Effect of age on tendon stem/progenitor cell telomerase activity and telomere length. Primary tendon derived cells were harvested from young or old rats and relative telomere length $(A)$ and relative telomerase activity $(B)$ measured. ${ }^{* *}$ indicates a significant difference $(p<0.001)$ compared to the corresponding tendons from younger animals. Data are presented as mean \pm SEM.

Given that we observed a loss in proliferative capacity in mature, tail tendon progenitor cells (Figures 1-3), we were curious if mature progenitor cells would exhibit shortened telomeres. As such, we measured telomere length and telomerase activity in young and mature tendon progenitor cells. We found no statistically significant differences in telomere length between differently aged progenitor cells from patellar, Achilles and tail tendons (Figure 7a). Relative telomerase activity was comparable between young and mature patellar and Achilles tendon progenitor cells (Figure $7 \mathrm{~b}$ ). In contrast, a significant drop in telomerase activity was found in mature cells derived from tail tendon (Figure $7 \mathrm{~b}$ ).

\section{Discussion}

In this study we looked at the effects of in vivo ageing on progenitor cells from three different rat tendons. Our 52 week old mature rats represented humans of around 30 years of age [40,41]. We chose this value because, according to epidemiological studies looking at Achilles tendon ruptures in the general public, the incidence of ruptured 
tendons is highest in the age group of 30-39 years [42,43]. It was therefore important to understand if age-related changes were already observable in the tendons of middle-aged rats. That such changes would be observable at 52 weeks was plausible, as worsened tensile properties of the human femur-anterior cruciate ligament-tibia complex were reported in both middle-aged and older adults [44].

Corroborative of work published by other groups $[14,15,18]$, we found a decrease in cell progenitor density in mature patellar, Achilles and tail tendons as compared to respective young tendons (Table 1). This difference reached statistical significance for both Achilles and tail tendons, with the tail tendon having the lowest cells/mg density (Table 1). Concomitant with the age-related loss of cell density, we noted a notable increase in tissue size with age for the patellar and Achilles tendons (Table 1). Since only samples of tail tendons were analysed, we were unable to compare the weight of mature and young tail tendons. Our data would suggest that an age-related increase in tendon size contributes to a loss in cell density. It may not fully account for it, however, as we also observed in increase in total cell number with age in patellar and Achilles tendons (Table 1).

Using a colony forming assay we have previously shown that rat tendons contain a subpopulation of stem/progenitor cells [26], a result confirmed by Bi et al. in mice and humans [45]. We have also previously found that the capacity of rat MSCs to form colonies declines with age [35]. Interestingly, whereas the progenitor cells from older tail tendons had a reduction in colony number, size and density in the present study, the Achilles and patellar tendons showed no significant agerelated reduction in either of these parameters (Figure 1). One possible explanation for this is that the progenitor cell niche in these tendons is more resistant to ageing or that patellar and Achilles tendons exhibit more robust repair mechanisms to counteract ageing damage. Despite the decreased colony number and size, mature tail tendon derived progenitor cells were able to grow at a rate similar to the Achilles tendon derived progenitor cells for the first 60 days (Figure 4). Both young and mature tail tendon progenitor cells were able to steadily undergo more than twenty passages (Figure 4 ). This would suggest that the age-dependent loss in colony number, size and density may be due to other factors besides growth rate.

Compared to our previous studies on MSCs [35-37], rat tendon progenitor cells showed relatively little evidence of age related cellular damage. There were no discernible differences in the levels of lipofuscin or ROS in any of the tendon derived progenitor cells tested and the levels of both parameters were low in all tested tendons (Figure 5). Unlike lipofuscin or ROS levels, progenitor cells from mature tail tendons exhibited a significant increase in carbonyl levels over young tail tendon progenitor cells. Carbonyl levels did not significantly change with age in progenitor cells from the patellar or Achilles tendons (Figure 5). This is in alignment with the general theme of the study, which is that tail tendons seem more prone to the deleterious effects of ageing than patellar or Achilles tendons. Achilles and patellar tendons are weightbearing tendons while the tail tendon is not weight-bearing and can be regarded as a positional tendon. It is possible that, because Achilles and patellar tendons are more frequently mechanically stimulated and are responsible for weight bearing, they possess more robust repair mechanisms which serve to combat ageing damage. Mechanical tension is required for optimal healing of injured tendons and it is known that mechanical loading induces significant changes in tendon gene expression $[46,47]$. As such, we find it reasonable to hypothesize that increased mechanical stimulation of patellar and Achilles tendons may make them more resilient to ageing than tail tendons.
In our previous studies on MCSs [35-37] we observed a decrease in SOD and glutathione activity with age. In contrast, we observed a significant increase in SOD activity in mature Achilles tendon progenitor cells as well as an increase in catalase activity in mature patellar tendon progenitor cells (Figure 6). Radak et al. similarly found that catalase and glutathione peroxidase activity increase with age in tendon tissue [48]. A possible explanation for the disparate ageing responses exhibited by MSCs and tendon derived progenitor cells may lie in their respective environments. Whereas the bone marrow environment is extremely well supplied with blood, nutrients and oxygen, the tendon is a poorly vascularised tissue and it has been reported that tendon cell metabolism becomes progressively more anaerobic with increasing age [49].

Our presented results show that, at an age where a decline in mechanical properties is measurable, the primary age-dependent difference common to all three tendons is a reduction in cell density (Table 1). This would mean that, in response to wounding or tissue damage, tendon progenitor cells would need to migrate further to a site of injury to promote a repair response. Advocating this is the finding that the ability of mouse tendon progenitor cells to migrate is reduced with increasing age [3]. It would also appear that, compared to tail tendons, Achilles and patellar tendon progenitor cells inhabit a privileged environment. Tail tendons exhibited a more drastic decrease in cell numbers and were the only tendon tissue in the present study to show increased protein oxidation with age.

Our data indicate that the type and age of tendon donor tissue used has important implications for clinical therapies utilizing tendon progenitor cells. Future studies should aim to further characterize progenitor cell populations in different tissues to identify the optimal tendon source to use for a given cell-based or tissue engineering therapy.

\section{Acknowledgement}

The work presented in this paper was made possible by funding from the German Federal Ministry of Education and Research (BMBF 1315883). We thank Michela Livrea and Muamer Hodzik for helping with our experiments measuring telomere length and telomerase activity. We additionally thank Sophia Garten for assisting with our tendon cultures and measurements

\section{References}

1. Tuite DJ, Renström PA, O'Brien M (1997) The aging tendon. Scand J Med Sci Sports 7: 72-77. [PubMed]

2. Buckwalter JA, Woo SL, Goldberg VM, Hadley EC, Booth F, et al. (1993) Softtissue aging and musculoskeletal function. J Bone Joint Surg Am 75: 15331548. [PubMed]

3. Arnesen SM, Lawson MA (2006) Age-related changes in focal adhesions lead to altered cell behavior in tendon fibroblasts. Mech Ageing Dev 127: 726-732. [PubMed]

4. Owens B, Mountcastle S, White D (2007) Racial differences in tendon rupture incidence. Int J Sports Med 28: 617-620. [PubMed]

5. Dressler MR, Butler DL, Wenstrup R, Awad HA, Smith F, et al. (2002)A potentia mechanism for age-related declines in patellar tendon biomechanics. J Orthop Res 20: 1315-1322. [PubMed]

6. Kader D, Saxena A, Movin T, Maffulli N (2002) Achilles tendinopathy: some aspects of basic science and clinical management. $\mathrm{Br} J$ Sports Med 36: 239249. [PubMed]

7. Rolf C, Movin T (1997) Etiology, histopathology, and outcome of surgery in achillodynia. Foot Ankle Int 18: 565-569. [PubMed]

8. Garatachea N, Pareja-Galeano H, Sanchis-Gomar F, Santos-Lozano A, FiuzaLuces C, et al. (2015) Exercise attenuates the major hallmarks of aging Rejuvenation Res 18: 57-89. [PubMed] 
Citation: Scutt N, Johnson AA, Scutt A, Stolzing A (2015) Tissue-Specific Ageing of Rat Tendon-Derived Progenitor Cells. J Stem Cell Res Ther 5: 309. doi:10.4172/2157-7633.1000309

9. Couppé C, Svensson RB, Grosset JF, Kovanen V, Nielsen RH, et al. (2014) Lifelong endurance running is associated with reduced glycation and mechanical stress in connective tissue. Age (Dordr) 36: 9665. [PubMed]

10. Ashcroft GS, Mills SJ, Ashworth JJ (2002) Ageing and wound healing Biogerontology 3: 337-345. [PubMed]

11. Strube P, Sentuerk U, Riha T, Kaspar K, Mueller M, et al. (2008) Influence of age and mechanical stability on bone defect healing: age reverses mechanical effects. Bone 42: 758-764. [PubMed]

12. Plate JF, Brown PJ, Walters J, Clark JA, Smith TL, et al. (2014) Advanced age diminishes tendon-to-bone healing in a rat model of rotator cuff repair. Am J Sports Med 42: 859-868. [PubMed]

13. Yu TY, Pang JH, Wu KP, Chen MJ, Chen $\mathrm{CH}$, et al. (2013) Aging is associated with increased activities of matrix metalloproteinase-2 and -9 in tenocytes. BMC Musculoskelet Disord 14: 2. [PubMed]

14. Stanley RL, Fleck RA, Becker DL, Goodship AE, Ralphs JR, Patterson-Kane JC (2007) Gap junction protein expression and cellularity: comparison of immature and adult equine digital tendons. J Anat 211: 325-334.

15. Nakagawa Y, Majima T, Nagashima K (1994) Effect of ageing on ultrastructure of slow and fast skeletal muscle tendon in rabbit Achilles tendons. Acta Physiol Scand 152: 307-313. [PubMed]

16. Spindler KP, Nanney LB, Davidson JM (1995) Proliferative responses to platelet-derived growth factor in young and old rat patellar tendon. Connect Tissue Res 31: 171-177. [PubMed]

17. Chard MD, Wright JK, Hazleman BL (1987) Isolation and growth characteristics of adult human tendon fibroblasts. Ann Rheum Dis 46: 385-390. [PubMed]

18. Ippolito E, Natali PG, Postacchini F, Accinni L, De Martino C (1980) Morphological, immunochemical, and biochemical study of rabbit achilles tendon at various ages. J Bone Joint Surg Am 62: 583-598. [PubMed]

19. Holmes I (1971) Variations in tendon cell morphology with animal, site and age. J Anat 108: 305-309. [PubMed]

20. Kohler J, Popov C, Klotz B, Alberton P, Prall WC, et al. (2013) Uncovering the cellular and molecular changes in tendon stem/progenitor cells attributed to tendon aging and degeneration. Aging Cell 12: 988-999. [PubMed]

21. Kregel K C, Zhang, H. J. 2007. An integrated view of oxidative stress in aging: basic mechanisms, functional effects, and pathological considerations. Am J Physiol Regul Integr Comp Physiol, 292, R18-36

22. Morikawa D, Itoigawa $Y$, Nojiri $H$, Sano H, Itoi E, et al. (2014) Contribution of oxidative stress to the degeneration of rotator cuff entheses. J Shoulder Elbow Surg 23: 628-635. [PubMed]

23. Radák Z, Takahashi R, Kumiyama A, Nakamoto H, Ohno H, et al. (2002) Effect of aging and late onset dietary restriction on antioxidant enzymes and proteasome activities, and protein carbonylation of rat skeletal muscle and tendon. Exp Gerontol 37: 1423-1430. [PubMed]

24. Naaldijk Y, Johnson AA, Ishak S, Meisel HJ, Hohaus C, et al. (2015) Migrationa changes of mesenchymal stem cells in response to cytokines, growth factors, hypoxia, and aging. Exp Cell Res 338: 97-104. [PubMed]

25. Scutt A, Reading L, Scutt N, Still K (2003) Mineralizing fibroblast-colony-forming assays. Methods Mol Med 80: 29-39. [PubMed]

26. Scutt N, Rolf CG, Scutt A (2006) Glucocorticoids inhibit tenocyte proliferation and Tendon progenitor cell recruitment. J Orthop Res 24: 173-182. [PubMed]

27. Scutt N, Rolf CG, Scutt A (2008) Tissue specific characteristics of cells isolated from human and rat tendons and ligaments. J Orthop Surg Res 3: 32. [PubMed]

28. Sheehy MR (2002) A flow-cytometric method for quantification of neurolipofuscin and comparison with existing histological and biochemical approaches. Arch Gerontol Geriatr 34: 233-248. [PubMed]

29. Currie GA (1981) Platelet-derived growth-factor requirements for in vitro proliferation of normal and malignant mesenchymal cells. Br J Cancer 43: 335343. [PubMed]

30. Cawthon RM (2002) Telomere measurement by quantitative PCR. Nucleic Acids Res 30: e47. [PubMed]

31. Wege H, Chui MS, Le HT, Tran JM, Zern MA (2003) SYBR Green real-time telomeric repeat amplification protocol for the rapid quantification of telomerase activity. Nucleic Acids Res 31: E3-3. [PubMed]
32. Herbert BS, Hochreiter AE, Wright WE, Shay JW (2006) Nonradioactive detection of telomerase activity using the telomeric repeat amplification protocol. Nat Protoc, 1, 1583-1590.

33. Izumi-Hisha H, Ito Y, Sugimoto K, Oshima H, Mori KJ (1990) Age-related decrease in the number of hemopoietic stem cells and progenitors in senescence accelerated mice. Mech Ageing Dev 56: 89-97. [PubMed]

34. López-Otín C, Blasco MA, Partridge L, Serrano M, Kroemer G (2013) The hallmarks of aging. Cell 153: 1194-1217. [PubMed]

35. Stolzing A, Scutt A (2006) Age-related impairment of mesenchymal progenitor cell function. Aging Cell 5: 213-224. [PubMed]

36. Stolzing A, Sethe S, Scutt AM (2006) Stressed stem cells: Temperature response in aged mesenchymal stem cells. Stem Cells Dev 15: 478-487. [PubMed]

37. Stolzing A, Jones $E$, McGonagle D, Scutt A (2008) Age-related changes in human bone marrow-derived mesenchymal stem cells: consequences for cell therapies. Mech Ageing Dev 129: 163-173. [PubMed]

38. Jung T, Bader N, Grune T (2007) Lipofuscin: formation, distribution, and metabolic consequences. Ann N Y Acad Sci 1119: 97-111. [PubMed]

39. Levine RL (2002) Carbonyl modified proteins in cellular regulation, aging, and disease. Free Radic Biol Med 32: 790-796. [PubMed]

40. Sengupta P (2013) The Laboratory Rat: Relating Its Age With Human's. Int Prev Med 4: 624-630. [PubMed]

41. Quinn R (2005) Comparing rat's to human's age: how old is my rat in people years? Nutrition 21: 775-777. [PubMed]

42. Leppilahti J, Puranen J, Orava S (1996) Incidence of Achilles tendon rupture Acta Orthop Scand 67: 277-279. [PubMed]

43. Lantto I, Heikkinen J, Flinkkilä T, Ohtonen P, Leppilahti J (2015) Epidemiology of Achilles tendon ruptures: increasing incidence over a 33-year period. Scand J Med Sci Sports 25: e133-138. [PubMed]

44. Woo SL, Hollis JM, Adams DJ, Lyon RM, Takai S (1991) Tensile properties of the human femur-anterior cruciate ligament-tibia complex. The effects of specimen age and orientation. Am J Sports Med 19: 217-225. [PubMed]

45. Bi Y, Ehirchiou D, Kilts TM, Inkson CA, Embree MC, et al. (2007) Identification of tendon stem/progenitor cells and the role of the extracellular matrix in their niche. Nat Med 13: 1219-1227. [PubMed]

46. Mendias CL, Gumucio JP, Lynch EB (2012) Mechanical loading and TGFchange the expression of multiple miRNAs in tendon fibroblasts. J Appl Physiol (1985) 113: 56-62. [PubMed]

47. Eliasson P, Andersson T, Aspenberg $P$ (2009) Rat Achilles tendon healing mechanical loading and gene expression. J Appl Physiol (1985) 107: 399-407. [PubMed]

48. Radák Z, Takahashi R, Kumiyama A, Nakamoto H, Ohno H, et al. (2002) Effect of aging and late onset dietary restriction on antioxidant enzymes and proteasome activities, and protein carbonylation of rat skeletal muscle and tendon. Exp Gerontol 37: 1423-1430. [PubMed]

49. Józsa L, Kannus P (1997) Human tendons: anatomy, physiology, and pathology Human Kinetics, Champaign, IL.

Citation: Scutt N, Johnson AA, Scutt A, Stolzing A (2015) Tissue-Specific Ageing of Rat Tendon-Derived Progenitor Cells. J Stem Cell Res Ther 5: 309. doi:10.4172/2157-7633.1000309 